\title{
نظرية أفعال العباد عند المعتزلة
}

\section{The Theory of Human Act According to the Mu'tazilites}

\author{
ABDULL RAHMAN MAHMOOD* \& MOHD HAIDHAR KAMARZAMAN ${ }^{1}$
}

\begin{abstract}
The Mu'tazilites emphasizes the concept of Divine justice and the responsibility of man. According to them, Allah should reward or punish human beings according to their deeds. They maintain that man decides upon and creates his acts, both good and evil. He deserves reward and punishment in the hereafter for what he does. This article focuses on the arguments of Mu'tazilites in defending their theory. It also reveals their arguments in defending that human beings are the only authors of their own acts. The 'Qiyas al-Gha'ib 'ala al-Shahid' has been widely used in their arguments.
\end{abstract}

Keywords: free will, human act, justice, Mu'tazilites, predestination

وقد وضع المعتزلة أصولا لمذهبهم وذهبوا إلي القول بالحرية انطلاقا من بعض هذه الأصول. ومنها أصلهم العدل، وانطلاقا من هذا الأصل ذهبوا إلي تقرير مبدأ الحرية الإنسانية، وذلك أن الله عادل لا يظلم، لأن الظلم قبيح في حقه تعالى. ومن المعروف أن القول بأن الإنسان ليست له قدرة مؤثرة في عمله الذي سوف يحاسبه الله عليه يتنافى مع القول بالعدل، إذ كيف يهاسب الله ويثيب أو يعاقب على فعل نفسه في العبد لا على فعل العبد. وهذا ظلم يجب أن يتنزه الله عنه. وبناء عليه فالعبد هو الفاعل للخير والشر والطاعة والمعصية، حتى يمكن الخروج عن هذا المخظور الذي هو نسبة الظلم إلي الله تعالى ولكي نفسح المحال لتحقيق عدل الله، لابد من تأكيد حرية الإنسان، ولأجل أن الإنسان يخلق فعله يستحق الله أن يوصف بالعدل، ولعل الذي حملهم على هذا القول ما رأوه من مقالات الجهمم بن صفوان وأصحابه في سلب الإنسان قدرته وجعله كالجماد بتحى الأفعال على يديه كما تجرى على الحجر (1994 Ahmad Amin). فمذهب المعتزلة إذن هو المذهب المقابل لمذهب جهم، حيث أصروا على أن يكون الفعل البشرى نتاجا خالصا لقدرة الإنسان. ومن تم كان المعتزلة شبه بحمعين على القول بتعلق الفعل البشرى بالفاعلية للإححداث والإيجاد دون شيء آخر (al-Shahrastani 1990). فإهم يرون أن الشرع والعقل قد حددا لنا

1 Abdull Rahman Mahmood*(Corresponding author), Ph.D., Senior Lecturer, Dept. of Theology and Philosophy, Faculty of Islamic Studies, Universiti Kebangsaan Malaysia, 43600 BANGI, Selangor, Malaysia, email: abrm@ukm.edu.my; Mohd Haidhar Kamarzaman, Lecturer, Dept. of Theology and Philosophy, Faculty of Islamic Studies, Universiti Kebangsaan Malaysia, 43600 BANGI, Selangor, Malaysia, email: haidhar@ukm.edu.my. 
ثواب الإنسان وعقابه في الآخرة ولم يكن ذلك إلا لأنه مسئول عما فعل من طاعة أو معصية، قال تعالى:

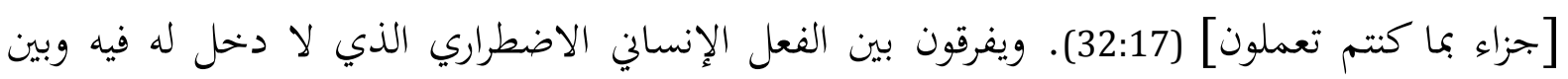

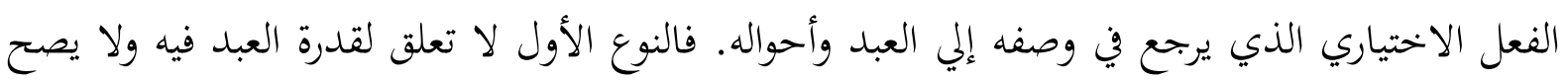

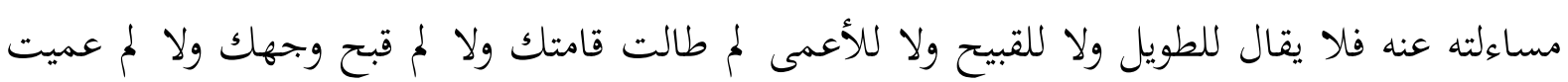

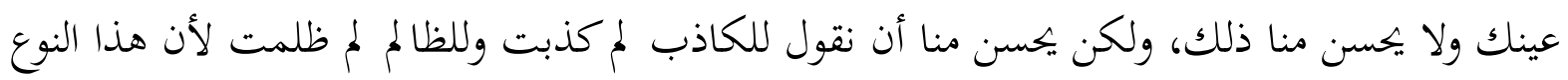
تتعلق به قدرة الإنسان عكس النوع الأول (al-Qadi `Abd al-Jabbar 1988).

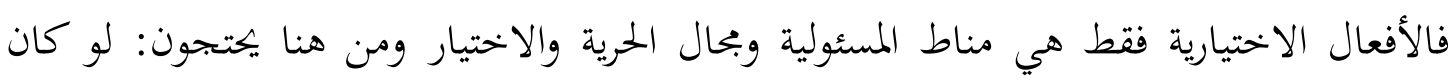
القضاء الأزلي قد حمل الإنسان على المعصية لما كان للتكليف أي معنى ولا للثواب والعقاب التهاب أي فائدة. ولماذا يكلف الإنسان بالأوامر والنواهي ما دام القضاء سوف يحمله قهرا على تنفيذ ما أراده الله لهم. أليس وله في هذا القول نوع من التجوير لله ويحمل أيضا في طياته نسبة العبث إلى فعله تعالى (al-Jalaynid 1981).

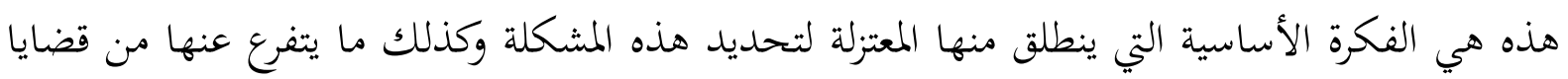

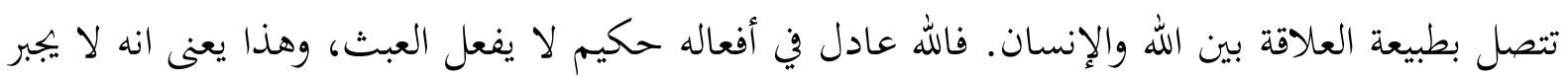

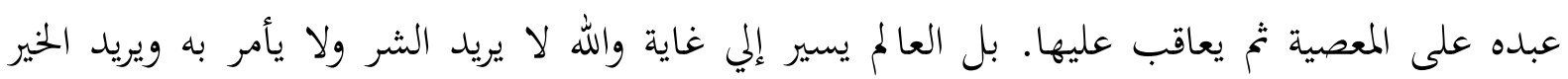

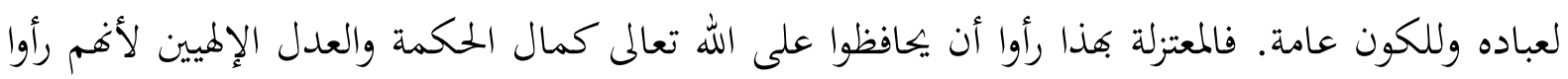

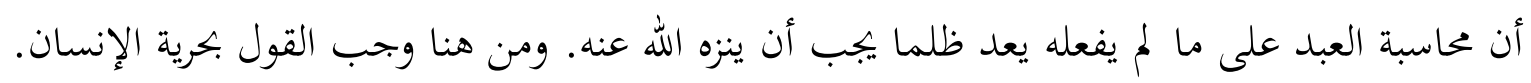

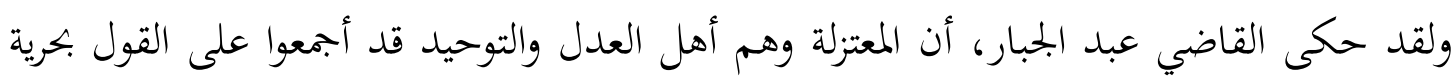

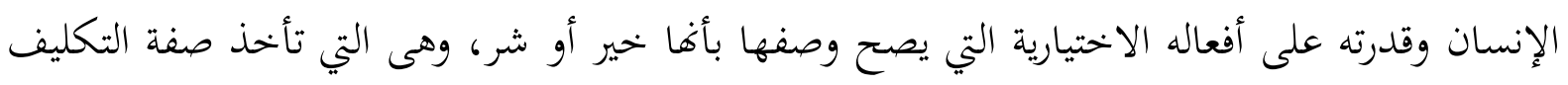

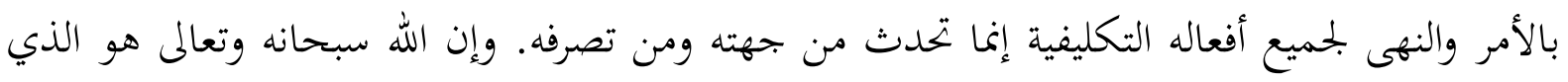

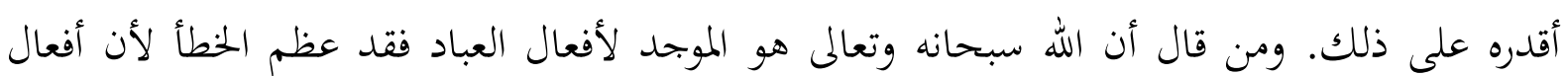

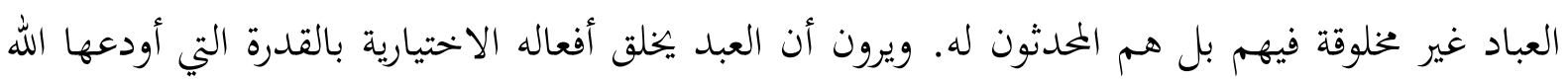

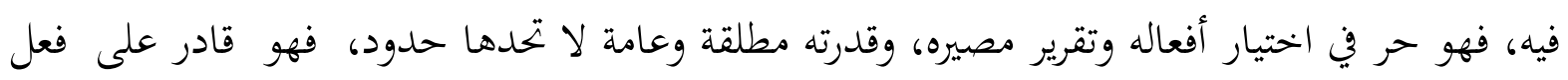

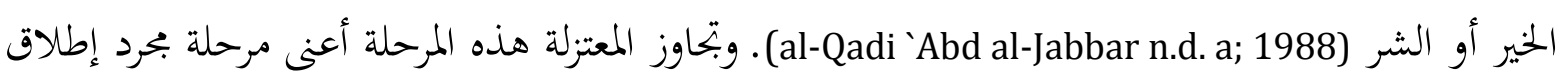

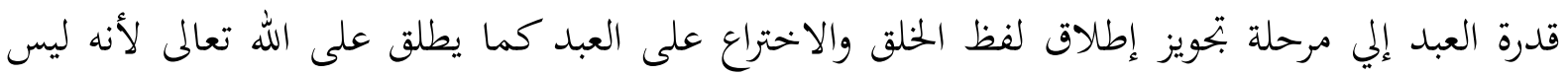
هناك ما يثبت أن لفظ الخلق والاختراع يختص بالله تعالى ولا يشاركه فيه غيره. 
وأول من أجاز إطلاق لفظ الحلق في حق العبد هو شيخهم أبو على الجبائي وأتباعه. يقول الشيخ الطيب وكان الأوائل من المعتزلة .كواصل بن عطاء وعمر بن عبيد. يتحاشون إطلاق الخالق في حق العبد واكتفاء بالموجد والمخترع ونحو ذلك، ثم رأى الجبائى وأتباعه أن معنى الكل واحد وهو المخرج من العدم إلي الوجود فتجاسروا على إطلاق الحنالق (al-Juwayni 1950; al-Tayyib 1348H). ومما بتحدر ملاحظته هنا أن المتأخرين من المعتزلة قد وضعوا مراده من استعمال لفظ الخلق وهو مخالف لما يقصد به أهل السنة والجماعة. حيث إن الخلق عندهم هو التقدير للأمور وترتيبها، وإلى هذا ذهب القاضي عبد الجبار في شرح الأصول الخمسة وصرح بأن الخلق ليس بأكثر من التقدير وقال: "واستعمال الخلق بمعنى التقدير معروف ومشهور في اللغة فيقال، خلقت الأديم" (al-Qadi `Abd al-Jabbar 1988). ثم بينوا السر في انصراف لفظ الخالق إلي الله تعالى دون الإنسان وكيف أن إجراءه على هذا النحو فقط إنما هو من جهة التعارف، كما لا يطلق قولنا (رب) إلا عليه. وإن كان كذلك فلا مانع من أن يجرى على غيره، وإنما لم يجر إلا عليه إزالة للإبهام. ولولاه لكان يمنع ذلك عن غيره. وذلك لان معنى الخالق إنما هو وقوع الفعل من فاعله مقدرا، وإن العبد قد يحدث الفعل بمقدار كما أنه تعالى يحدث كذلك، فيجب أن يوصف بهذا الوصف، فإذا ثبت ذلك كان عندهم أن الحركة المكتسبة مخلوقة فيجب أن يكون لها خالق، وخالقها قد يكون الإنسان كما أن خالق الحركة الضرورية هو الله سبحانه وتعالى (al-Qadi `Abd al-Jabbar n.d. a). هكذا نرى أهم آثروا إطلاق لفظ الخلق على أفعال الإنسان وآثروا الحد من إطلاق القدرة الإلهية حفاظا على إثبات القدرة الإنسانية، وعندما بدا لمم التعارض بين إثبات شمول القدرة الإلهية ووجود القدرة للإنسان، قرروا أن للإنسان قدرة مستقلة كاملة في فعلها، ولذلك جاءت تحديداتم للقدرة الإنسانية وماهيتها وتعلقها بالفعل جاءت كلها مؤكدة لاستقلالما وحريتها بالرغم من اختلافهم في مفهومها كما سنرى فيما بعد. ويقرر القاضي عبد الجبار: "أن الفعل يتعلق بفاعله. فمن غير المعقول أن تتعلق أفعال العباد بالذات الإلهية ولو كان الأمر خلاف ذلك لجاز لنا تعليق الفعل بفاعلين والمقدور بقادرين وهذا بينا سقوطه في باب القدرة، فالإنسان فيما وقع منه كان الفعل منه لا محالة وهو حادث من جهته ولا يمكن أن ننسب هذه الأفعال إلى الله تعالي لأن نسبتها إلى الله يلحق به أفعال النقص والعجز والشرور. وكل هذا مما يقبح نسبته إلى الله تعالي، فلابد من أن تكون هذه الأفعال من صنع الإنسان ومخلوقة له وتقع تحت قدرته، لأها

لو كانت مخلوقة لله لصح أن يوجدها وإن لم يقدر العبد عليها" (al-Qadi `Abd al-Jabbar n.d. a). فالمعتزلة إذن يرون أن الإنسان فاعل مختار حر الإرادة يتصرف بهذه القدرة التي منحته الله سبحانه وتعالى، ويوجهها حسبما يريد في خلق أفعاله، فهم يثبتون للقدرة الانسانية صلاحية الخلق والإيجاد، لأفم 
يعتقدون أن القادر علي الشيء لابد له من التأثير في مقدوره ويجب أن يتعين ذلك التأثير في الوجود، لأن

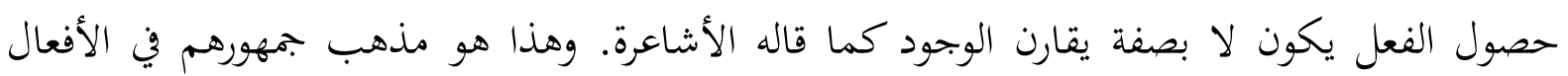

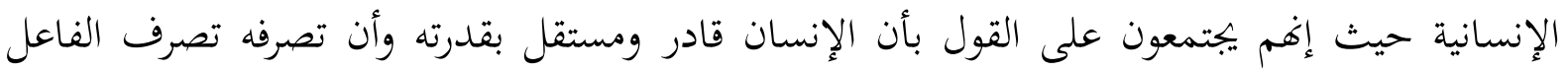
المختار، وأن الأفعال يتعلق به ويقع على حسب قصده، وأن جهة تعلق هذه الأفعال بالناس الفاعلين لها

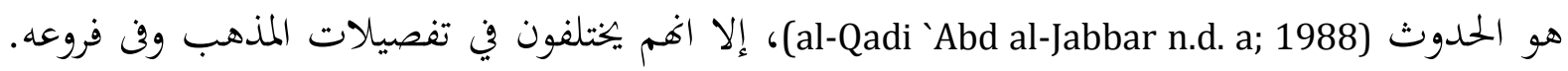
واختلفوا فيما بينهم في تحديد دور الفاعلية الإنسانية في الفعل.

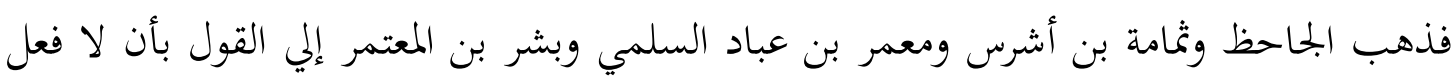

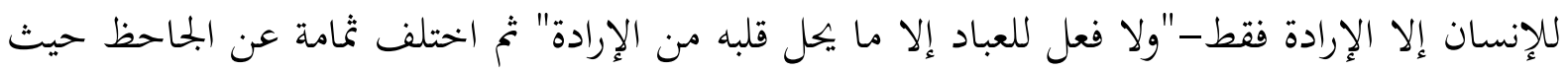

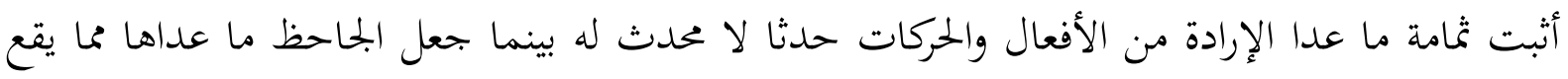

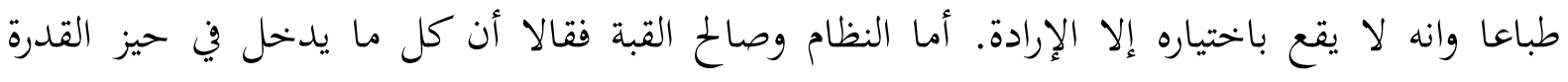
الإنسانية فهو من فعل الإنسان وما جاوز قدرته فلا يعد من فعله، بل يكون خلقا لله تعالى بمعنى أن الله الله

طبع الحجر طبعا وخلقه خلقا، إذا دفعته ذهب (al-Qadi `Abd al-Jabbar n.d.; n.d. a). وقد اختلف الباحثون في فهم هذا الرأي الذي صدر عن النظام والجاحظ بشأن الطباع. فرأى إلى

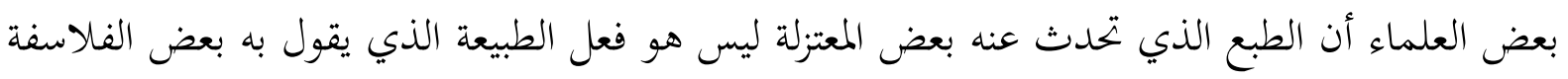

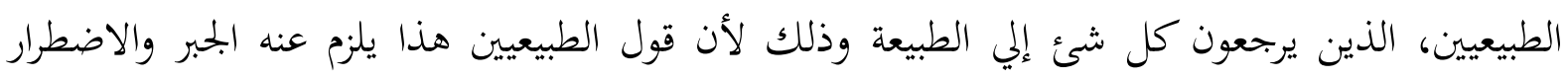

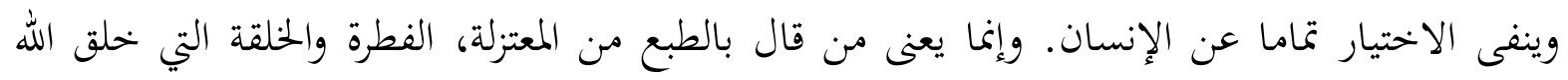

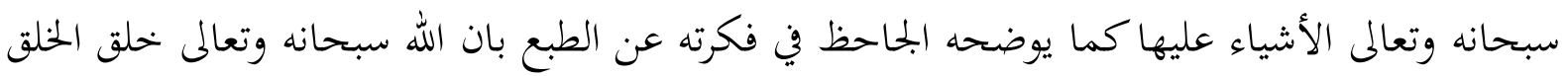

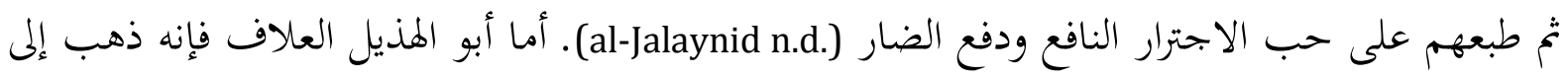

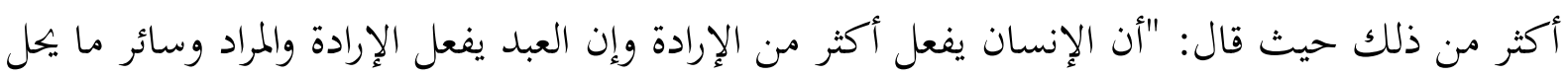

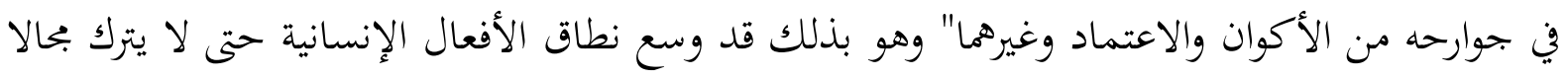

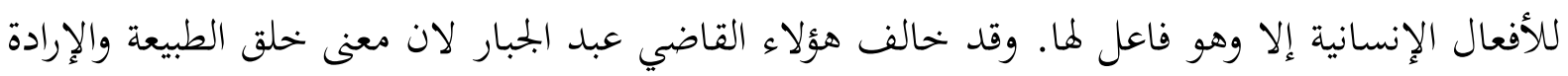

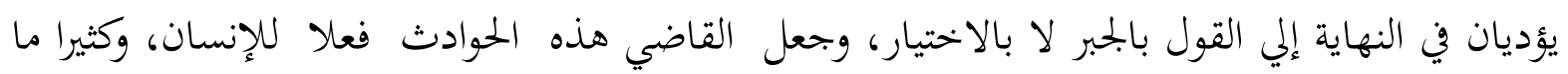

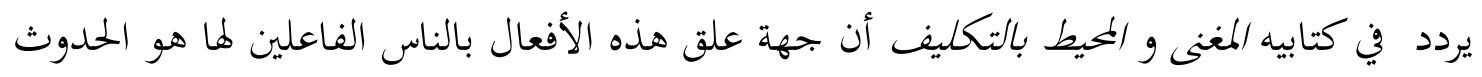


(al-Qadi `Abd al-Jabbar n.d. a; 1988). وبتحدر الملاحظة هنا، أن القاضي عبد الجبار هو من مفكري المعتزلة المتأخرين الذي وصلت إلينا معظم كتبه. وقد خصص جزءا كبيرا من مسالة خلق الأفعال في موسوعته المغنى وخاصة في الجزء الثامن وكذلك في كتابه "الحيط بالتكليف"

وقد حدد القاضي عبد الجبار (al-Qadi `Abd al-Jabbar n.d.; n.d. a) في كتبه العناصر التي لابد أن توجد في الأفعال الإنسانية. وهذه العناصر تقوم على ثلاث دعائم أساسية بحيث لو توفرت في فعل فهو منسوب إليه؛ فقال: "فإذا وقع الفعل بحسب دواعي الفاعل وقصوده مع السلامة وانتفى بحسب كراهيته وصرفه مع السلامة فهو فعله". ونستطيع أن نقول، إن القاضي عبد الجبار يشترط لكي يتحقق نسبة الفعل الى فاعله عدة شروط:

أولا: أن يقع الفعل حسب دواعينا أي حسب ما نعلمه أو نعتقده أو نظنه من نفع لنا في الفعل أو دفع الضرر. فالعلم والمعرفة هما الشرط الأول لنسبة الفعل إلي الفاعل. يقول: إنه لابد من أن يكون المكلف "عالما بالفعل قبله علي وجه يمكنه من القصد إلى أدائه دون غيره. فان لم يتم ذلك إلا بتقدم العلم بأوقات احتيج إليه فيها وان تم ذلك بتقدمه بوقت واحد كفي".

ثانيا: أن يكون له الإرادة والاختيار. فالإنسان يعلم من نفسه أنه مريد كما يعلم من نفسه انه معتقد وظان ومشته. فالمخصص لوقوع أحد الممكنات دون جميعها هو الإرادة، وهى علة وقوع الفعل على وجه معين دون سائر الوجوه التي يمكن أن يقع بها. يقول القاضي: "وجُحل ما يتصرف المرء فيه من هذه الأفعال تؤثر فيه الإرادة دون غيرها".

ثالثا: وجود الاستطاعة والقدرة: فالفعل لا يتحقق عمليا إلا إذا كان الفاعل قادرا عليه، وإذا لم تكن القدرة حاصلة فإن الفعل لا يخرج عن كونه مقدورا للفاعل دون أن يكون متحققا من الناحية العملية. ولا يمكن إرجاع هذا التحقيق إلا إلي القدرة الإنسانية التي تحقق الفعل من جهة تعلقه بالفاعل، يقول القاضي عبد الجبار: "فالذي يقتضيه قادرا هو حدوث الفعل وخروجه من العدم إلي الوجود" (Dughaym 1992; al-Qadi`Abd al-Jabbar n.d.a).

ويشير القاضي حول هذه الشروط الثلاثة أن ما يجصل عليه بالفاعل على قسمين: أحدهما يجصل عليه من حيث كان قادرا فقط، والثاني يجصل عليه لأحوال أخر تخصص بها من كونه عالما مريدا وكلاهما يقال فيه أنه بالفاعل، ألا ترى أنا نقول في كون الفعل محكما: إنه بالفاعل من حيث كان عالما بكيفيته ونقول في الخيّر: إنه صار خيّرا لكونه مريدا: وحدوث ذلك أجمع يرجع إلي كونه قادرا" ثم لتمام القدرة على تلى 
الفعل يقرر القاضي ضرورة زوال الموانع بين الفاعل وبين الفعل، أي أنه بجانب القدرة والعلم والشهوة والنفار والإرادة يجب أن يكون المكلف "مخلى بينه وبين فعل ما كلف" (al-Qadi `Abd al-Jabbar n.d. a).

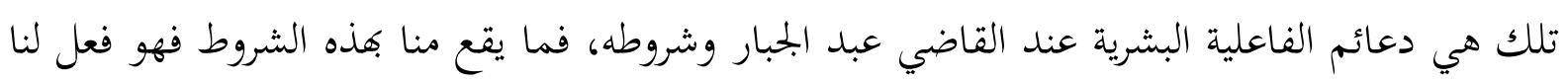

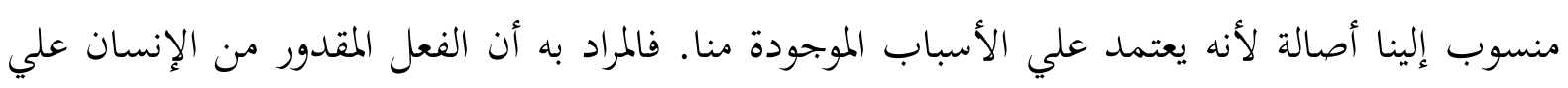

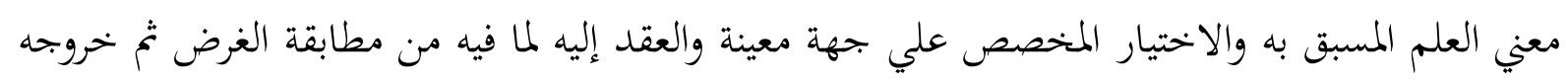

إلى حيز الوجود بالقدرة. وعلي هذا يتم قدرة الفعل من جهة تعلقها بالفاعل (al-Dusuqi n.d.).

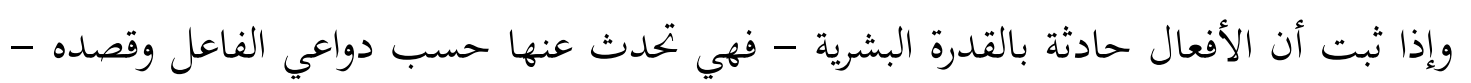

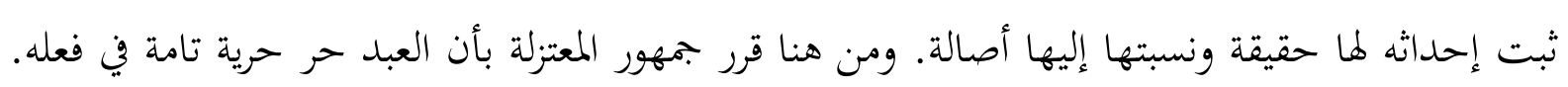

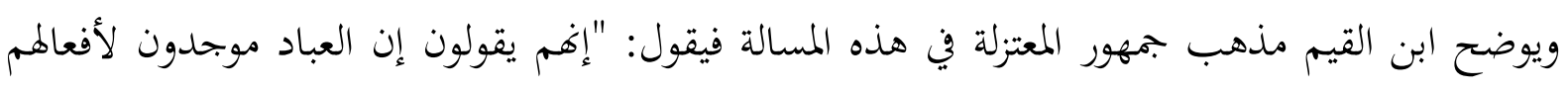

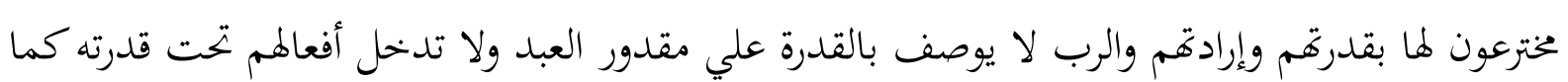

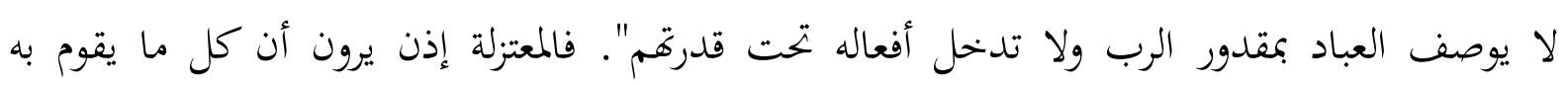
الإنسان هو صنعه وخلقه وإبداعه، ولكن مرتبته في الخلق لا تسمو بحال ما إلى مرتبة الخلق الإلهي.

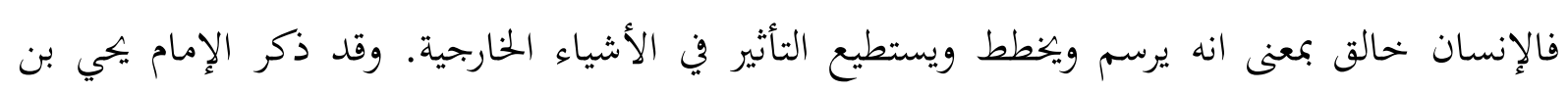

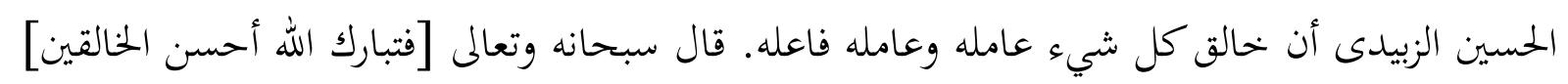

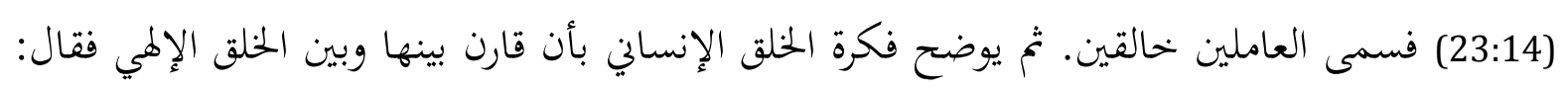

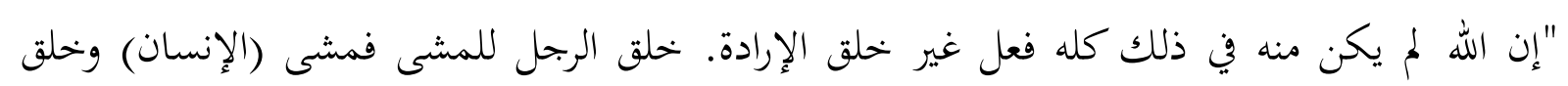

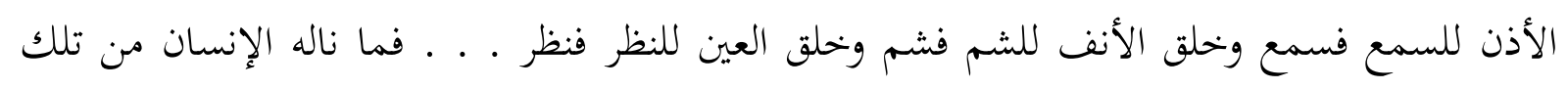

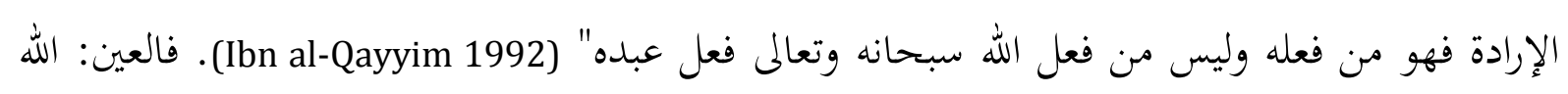

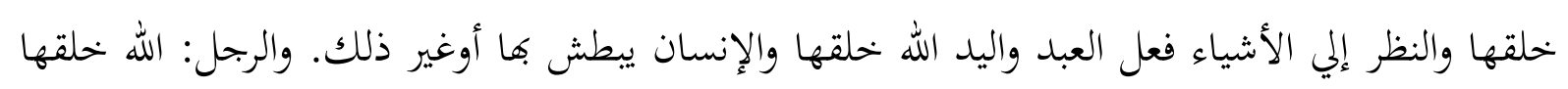

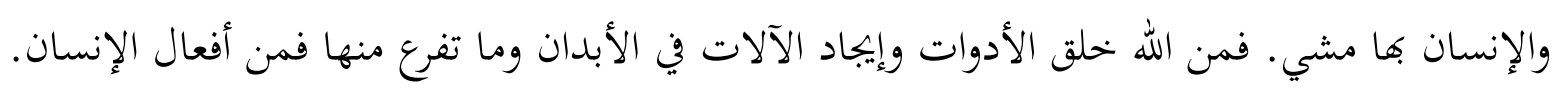

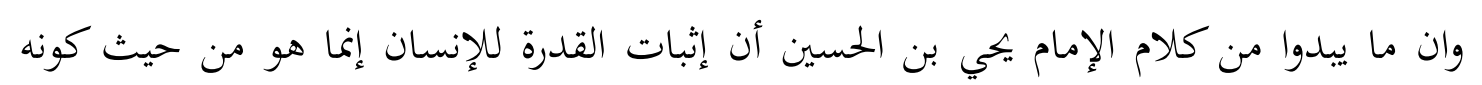

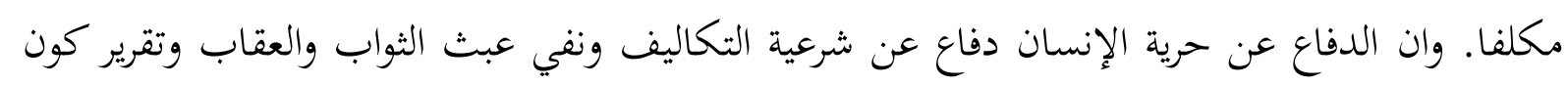

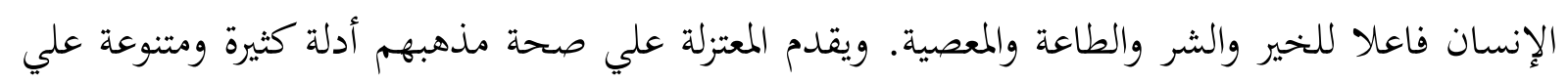

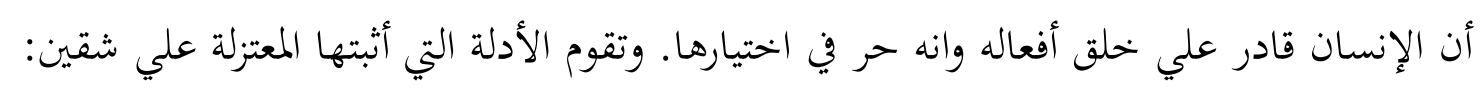

$$
\text { الشق الأول: يتمثل في إثبات المذهب عقلا وشرعا . }
$$


الشق الثاني: يتمثل في نقض مذهب خصومهم من الاشاعرة والجبرية الذين يرون أن أفعال

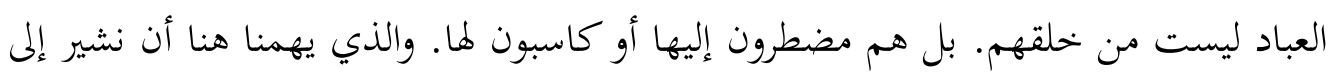

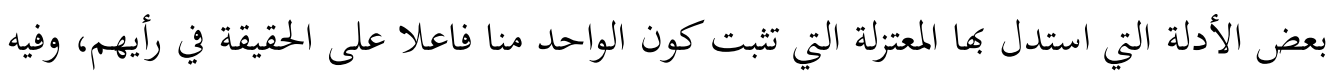

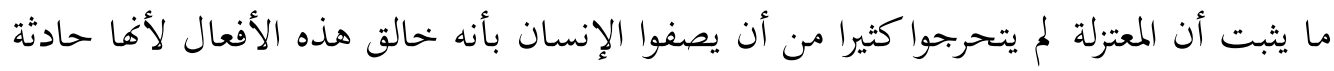
منه بقدرته و متعلقة علي جهته وقصوده ودواعيه.

والمعتزلة في سبيل الاستدلال على حرية أفعال العباد طائفتان: الأولى: أبو الحسين وأتباعه. وهم

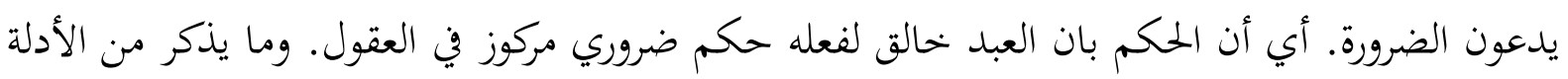

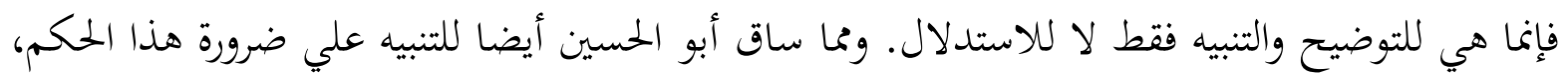

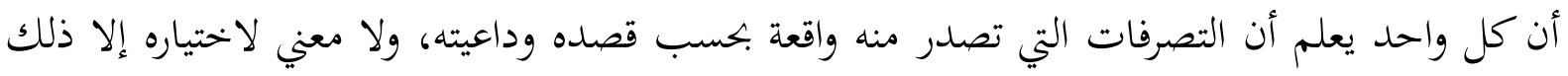

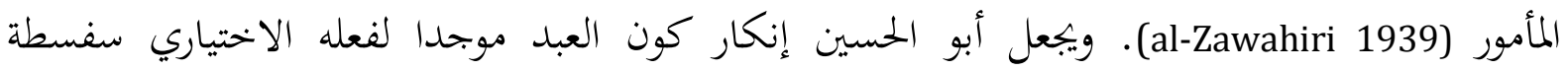

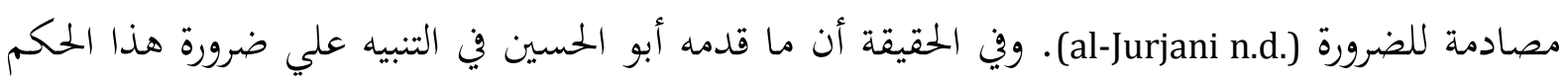

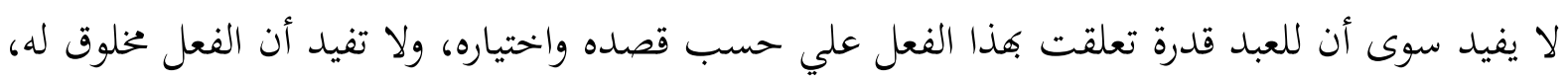

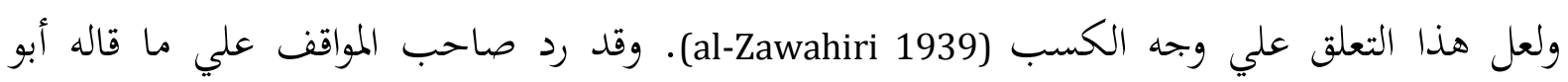
الحسين قائلا: "إن من كان قبله من الأمة كانوا بين منكرين لإيجاد العبد فعله ومعترفين به مثبتين له له

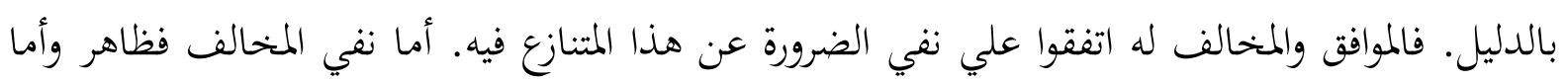

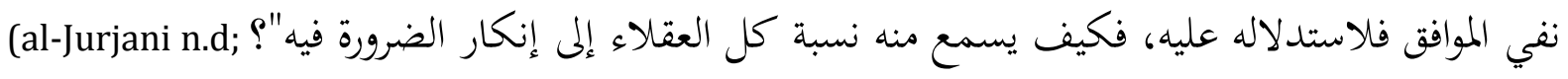
.al-Razi 1987) أما غير أبي الحسين فقد استدلوا بأدلة عقلية ونقلية. ومن هذه الأدلة: 1. انه لو كانت أفعال العباد بخلق الله تعالي وإيجاده لكان فاعلا لها. ولو كان فاعلا لها لكان

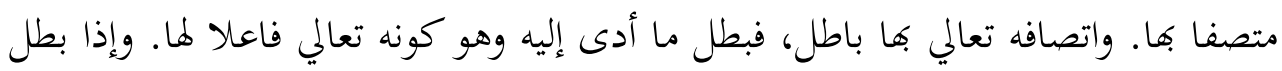

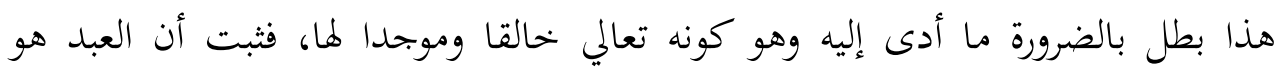
الخالق والموجد لها إذ لا واسطة (al-Qadi `Abd al-Jabbar 1988; al-Zawahiri 1939). 2. إننا نفصل بين المحسن وبين المسيء وبين حسن الوجه وقبحها، فنحمد المحسن علي إحسانه

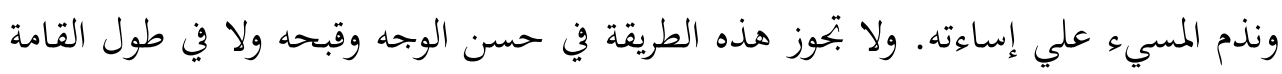

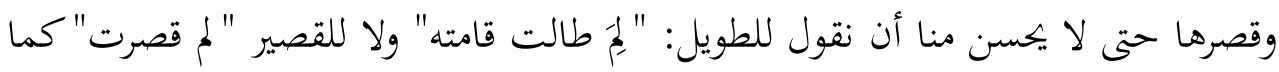


يحسن منا أن نقول: للظالم: "لم ظلمت" وللكذاب: "لم كذبت" فأن أحدهما متعلق بنا وموجود من جهتنا بخلاف الآخر، وإلا لما وجب هذا الفصل، ولكان الحال في طول القامة وقصرها كالحال في الظلم والكذب (al-Dusuqi n.d.; al-Zawahiri 1939). 3. إن الفعل يقع بالدواعي والقصود منا ومادامت هذه الدواعي والقصود محتاجة إلينا في الحدوث فما يقع بها أولى أن تكون حاجته إلينا في الحدوث، وهذا هو دليل القاضي لإثبات أن الفعل إنما حدث من جهتنا علي جهة الحدوث، ثم أضاف إلى هذا الدليل بدليل آخر مفاده: أن الوجه الذي يحتاج إلينا الفعل فيه هو الحلدوث، لان العلة والسبب في حاجة الفعل إلينا هو الحدوث أي أن دواعينا وقصودنا إنما توجد لإحداث الفعل. فعلة الحدوث هي دواعينا. ونخن نعلم انه يقف علي هذه الدواعي، بدليل حدوث الفعل بوجودها وانتفائه بانتفائها (al-Qadi `Abd al-Jabbar n.d.) 4. لو كان الله هو الخالق لأفعال العباد الاختيارية لزم أن يكون هو فاعل القبائح لأنه إذا كان خالقا لما وفيها القبائح لزم ما ذكرنا من قبح بعثة الانبياء ويرتفع المدح والذم وغير ذلك. وذلك يوجب أن لا تقع لهم ثقة بكتاب الله وان يجوزوا أن يبعث إليهم رسولا كاذبا يظهر المعجزة عليه ليضلهم عن سواء السبيل ويدعوهم إلى الكفر ويصرفهم عن الإسلام لأنه

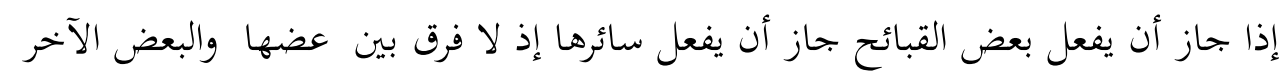
في القبح (al-Qadi `Abd al-Jabbar 1988).

وهذه بعض الأدلة العقلية التي ساقها القاضي عبد الجبار في كتبه المغنى والمحيط بالتكليف والأصول الخمسة . وقد لخص الإمام فخر الدين الرازى في كتابه المطالب العالية ما يدور في كتبهم من الأدلة حول أربعة شبهات ثم ناقشها مناقشة مستفيضة، وهذه الشبهات هي: (1) أن وجود أفعالنا دائر مع حصول قصودنا وإرادتنا فوجب أن يكون وقوع هذه الأفعال بها، (2) أن المكنة من الفعل والترك أمر وجداني اضطراري وكون الله تعالى موجدا لأفعال العباد يبطل هذا الوجدان، (3) أن العبد لو لم يكن موجدا لأفعال نفسه يلزم أن يكون تكليفه جاريا بحرى تكليف العاجز، وذلك قبيح في العقل، ولزم كونه تعالى خحالقا لهذه القبائح ويشتم نفسه وكل ذلك قبيح في العقول، (4) انه لو لم يكن العبد موجدا

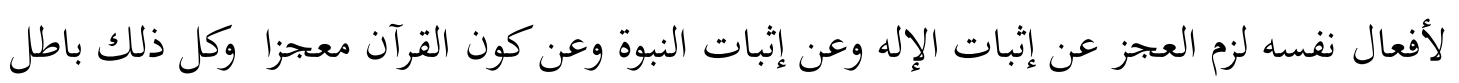
.(al-Razi 1987) 


\section{الأدلة النقلية}

إن المعتزلة لا يعتمدون على الأدلة النقلية إلا لمحرد تدعيم وتوكيد ما توصلت إليه عقولهم، ولأجل ذلك فإن

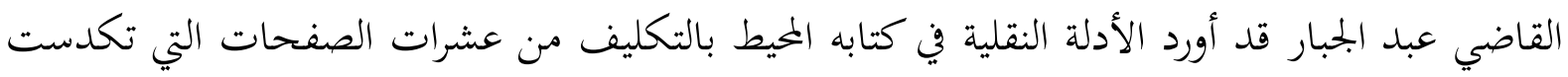

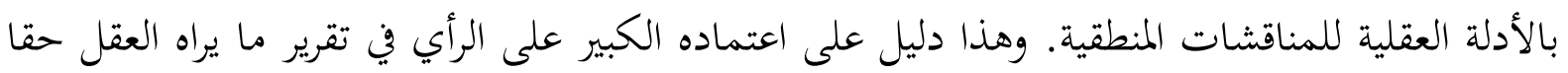

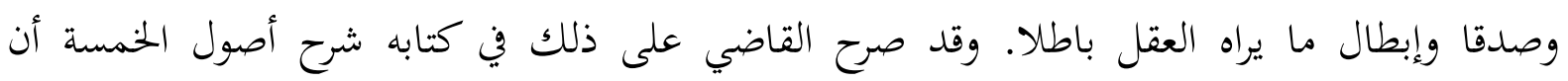

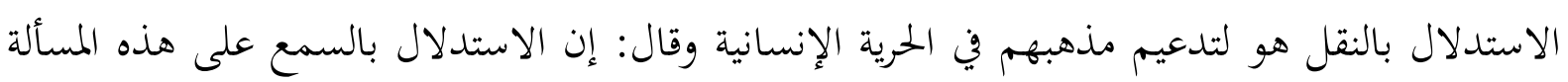

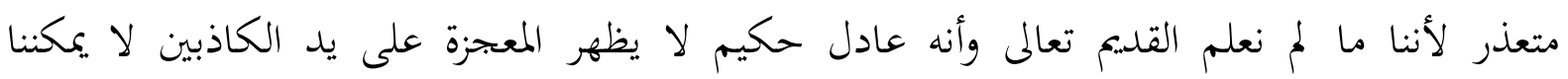

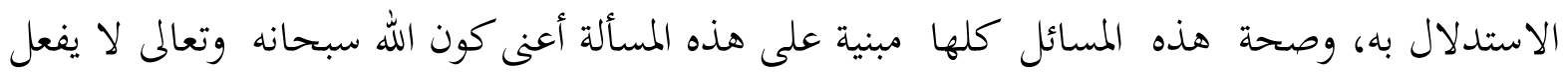

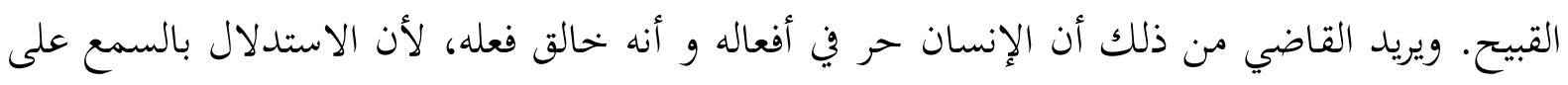

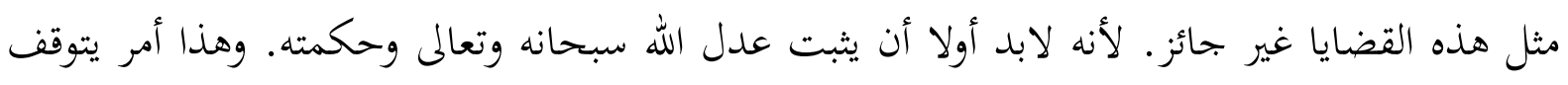

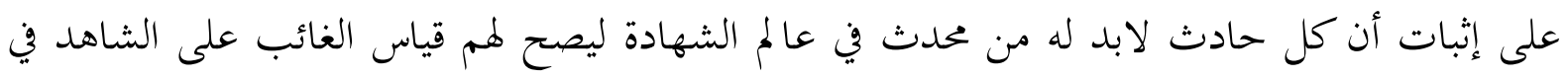

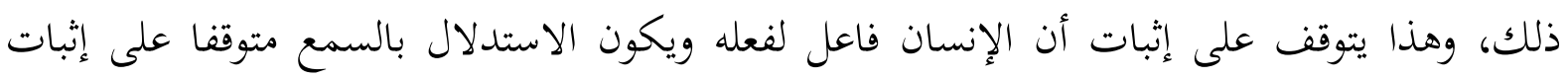
العدل والحكمة وهذا يؤدى إلي الدور الباطل (al-Qadi `Abd al-Jabbar n.d.; n.d. a; 1988).

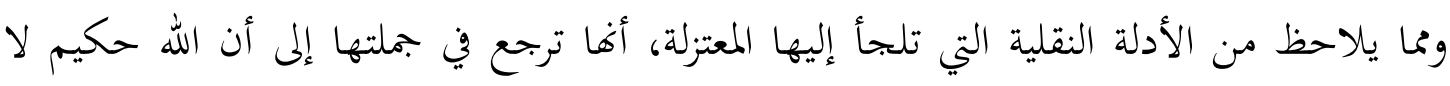

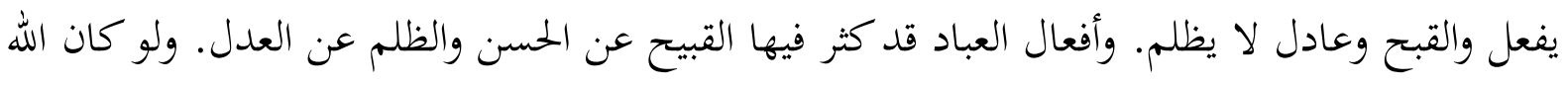

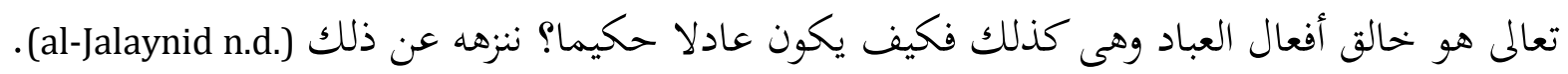

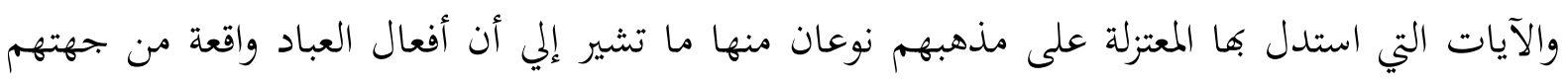

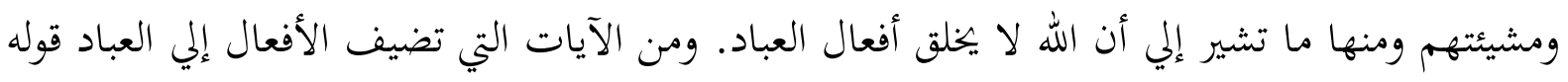

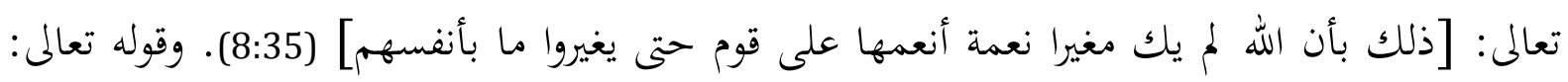

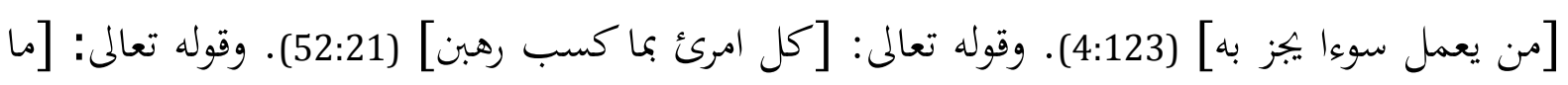

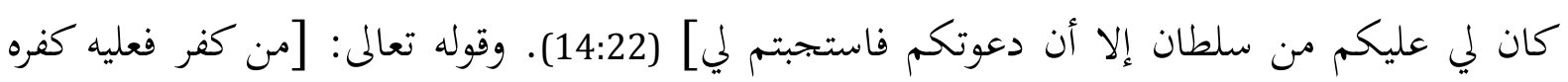
ومن عمل صالحا فلأنفسهم يمهدون] (30:44).

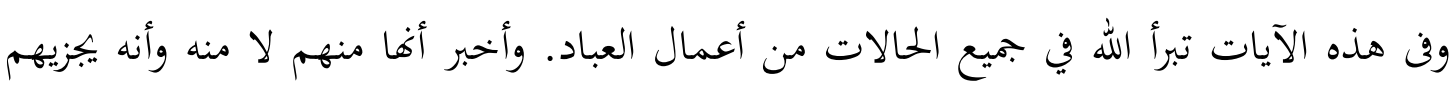

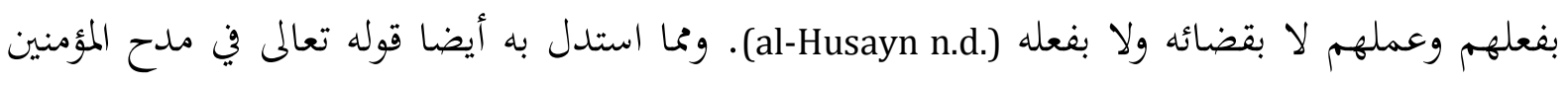
على الإيمان وذم الكافرين على الكفر ووعد الثواب علي الطاعة و العقاب علي المعصية، ومنها قوله تعالي: 
[اليوم بجزى كل نفس بما كسبت] (40:17). وقوله تعالى: [هل بتزون إلا بما كنتم تعملون] (27:90).

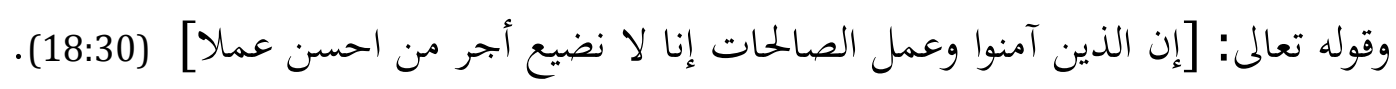

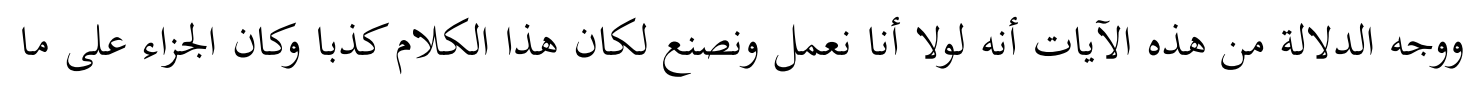

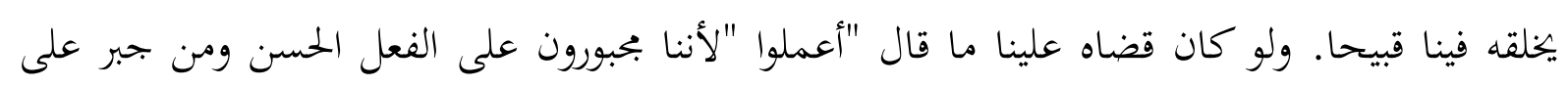

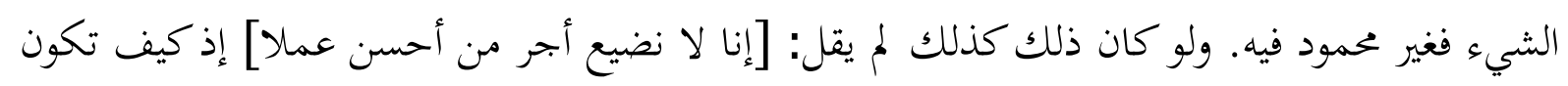
قد أحسنا العمل وهو المحسن لنا و الحاتم علينا (al-Husayn n.d.; al-Qadi `Abd al-Jabbar 1988).

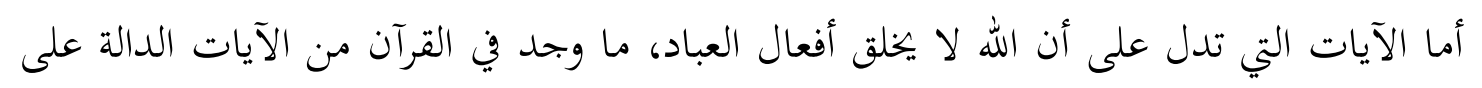

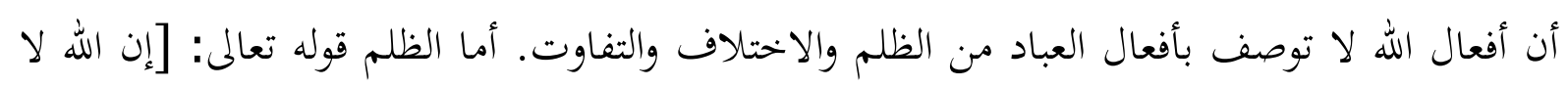

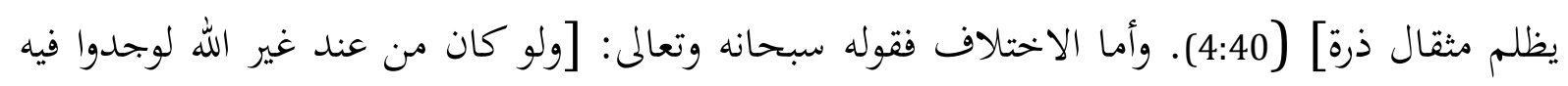

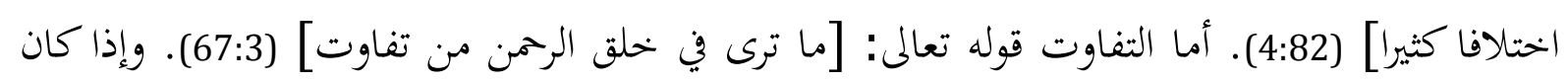

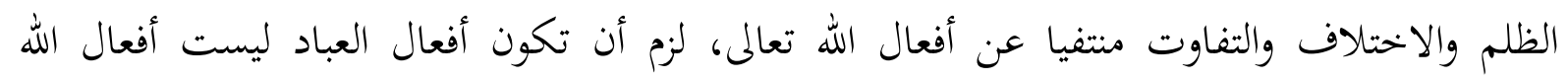

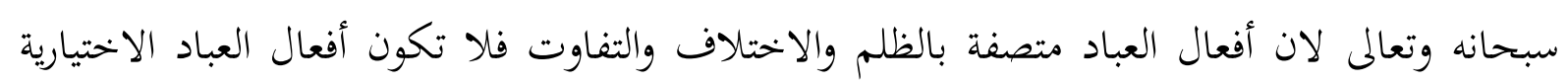

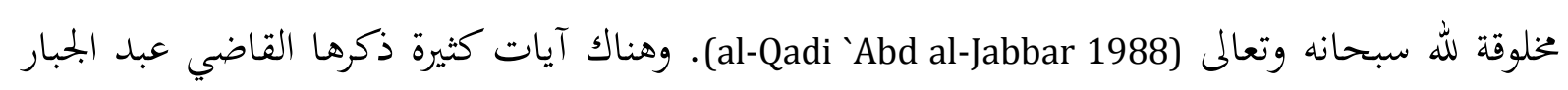

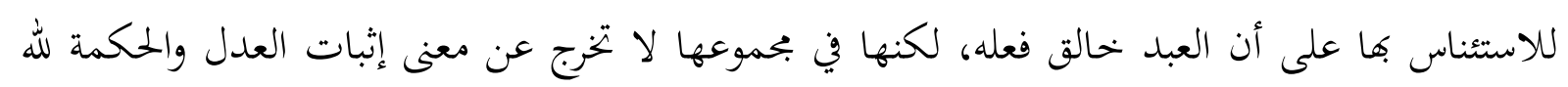
تعالى. وأن إثبات ذلك عقلا ونقلا يعنى أن العبد حر في فعله.

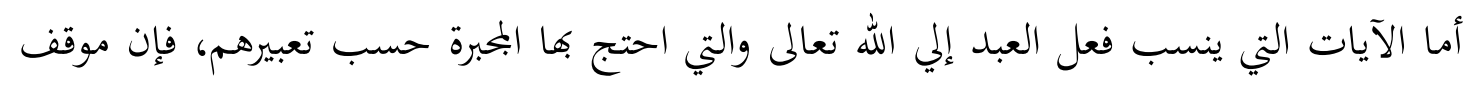

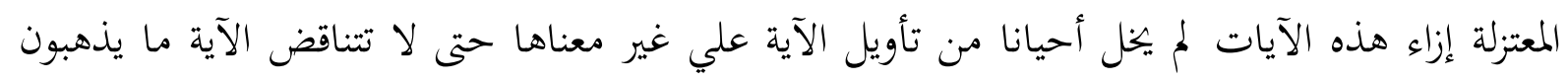

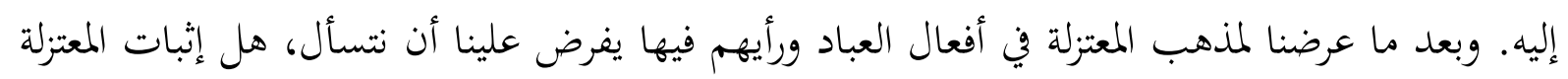

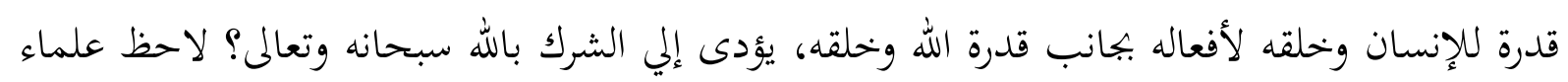

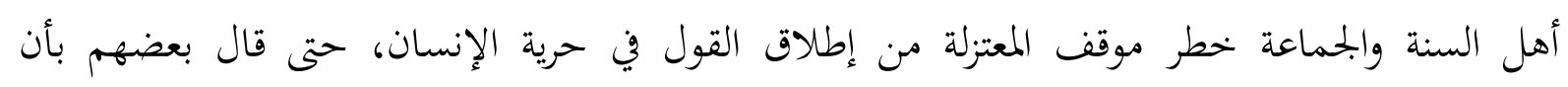

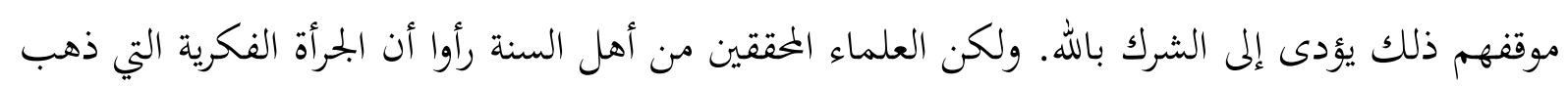

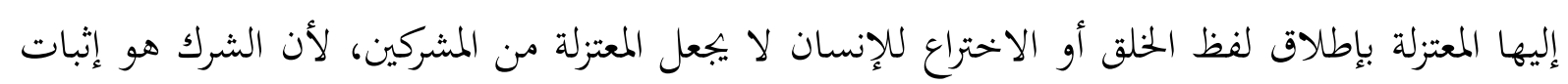

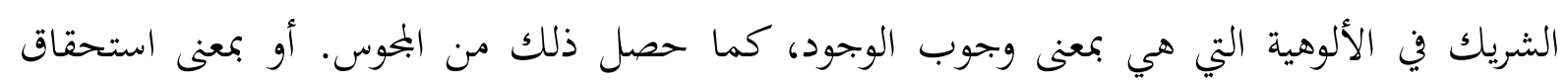

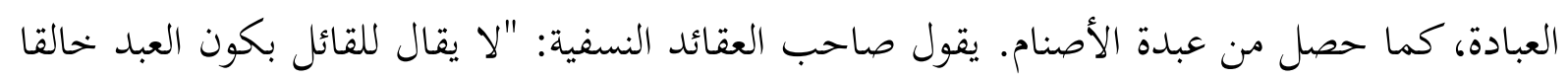

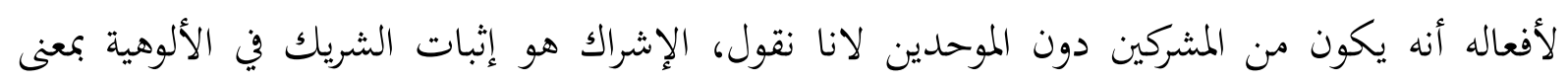


وجوب الوجود كما للمجوس أو بمعنى استحقاق العبادة، كما لعبدة الأصنام. والمعتزلة لا يثبتون ذلك. بل لا يجعلون خحالقية العبد كخالقية الله لافتقاره إلي الأسباب والآلات التي هي بخلق الله al-Taftazani) (1987. إذا فإن الإلزام المتجه للمعتزلة بالشرك مدفوع، لان مفهوم الشرك هو اعتقاد أن لغير الله أثرا فوق ما وهبه الله من الأسباب الظاهرة وأن لشئ من الأشياء قدرة على ما خرج عن قدرة المخلوقين al-Husayn)

\section{التعقيب}

إن الناظر في موقف المعتزلة من مشكلة أفعال العباد يجد اهم قد قروا ما قروه انطلاقا من أصولمم التي لا يجيدون عنها في تناول هذه المشكلة وهى مبدأ العدل والحكمة. وبناءا على ذلك قرووا أن أفعال الله يجب إيب أن تجرى داخل إطار العدل والحكمة بمفهومهما الخاص عندهم، وهو مفهوم لا يختلف كثيرا عما يجرى في عالم الشهادة، وقالوا بموجبه أن للعبد قدرة على فعله وحريته في اختياره له. وجانب آخر فاهم قد اهتموا بالجوانب الخلقية في الإنسان وحملوه نتيجة عمله، واشتد حرصهم على التكاليف الشرعية، وأخذوا منها دليلا على حرية الإنسانية واعتمدوا على ذلك اعتمادا كبيرا إلي درجة أن نفى التكاليف عندهم يساوى نفى الحرية كما أن نفى الحرية يساوى نفى التكاليف. فالتكاليف والحرية متلازمان وجودا وعدما، فمتى ارتفع أحدهما ارتفع الآخر.

وبناءا على ذلك رأوا أن يحافظوا على كمال الحكمة والعدل الإلهيين لان محاسبة العبد على ما لم يفعله يعد ظلما يجب أن ينزه الله عنه، وقد بالغ المعتزلة في تحقيق عدل الله بمفهومهم حتى يصل بهم الأمر إلي إخراج بعض الممكنات عن مدى قدرة الله تعالى، بل ذهب بعضهم أن الله ليس يمنع منه وقوع الظلم والقبح فقط، بل يزيد على ذلك فينفى قدرة الله على الظلم، فلقد ذهب النظام إلي أن الله "لا يقدر على أن يفعل بعباده خلاف ما فيه صلاحهم، ولا يقدر أن ينقص من نعيم أهل الجنة ذرة لان نعيمهم صلاح لمم ولا يقدر أن يزيد يي عذاب أهل النار ذرة، ولا ينقص من عذابهم شيئا" (al-Baghdadi 1988). وعلى أساس مبدأ العدل والتوحيد أيضا، آثروا إثبات القدرة البشرية وإن أدى هذا في زعمهم إلي الحد من القدرة الإلهية. وإذا كانت الجبرية قد آثروا القول بالفاعلية الإلهية المطلقة ونفت الفاعلية البشرية، فان المعتزلة لم تكن إلا المذهب المقابل لما، حيث أصروا على القول بالفاعلية البشرية منسوبا إلى الإنسان وأثرا مستقلا لقدرته. ومن تمح كان المعتزلة على ما يشبه الإجماع في قولمم بأن تعلق الفعل البشرى بالقدرة البشرية في 
الإحداث والإيجاد دون أي شيء آخر، بل افم أقاموا أصولمم على هذه القضية، ذلك لان إثبات فاعل قادر في الشاهد يعد مقدمة ضرورية ينبني عليها إثبات فاعل قادر في الغائب.

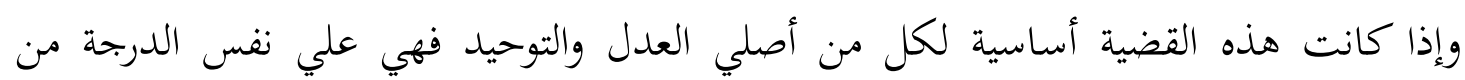

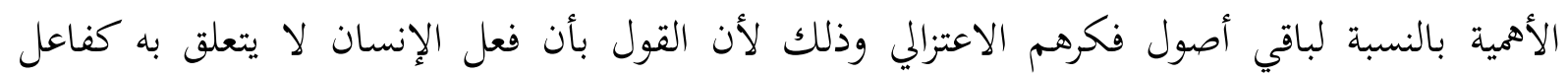

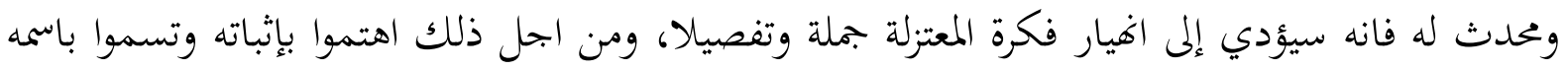

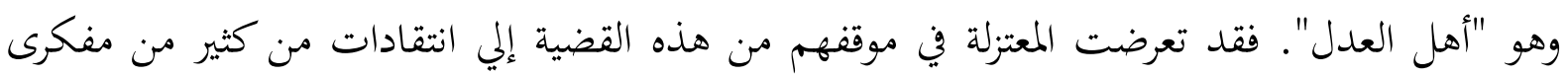

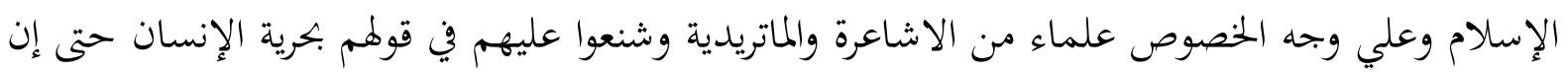
بعض العلماء اتمهم بأفهم خارجون عن الملة. والحقيقة أن موقفهم في هذه المسألة يحتاج إلى مزيد من الفهم والتأمل حتى نكون أكثر ألماء إفصاحا

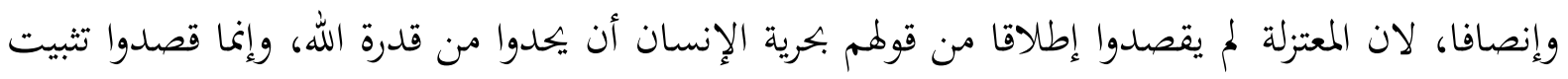

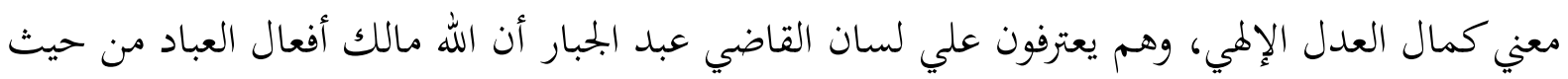

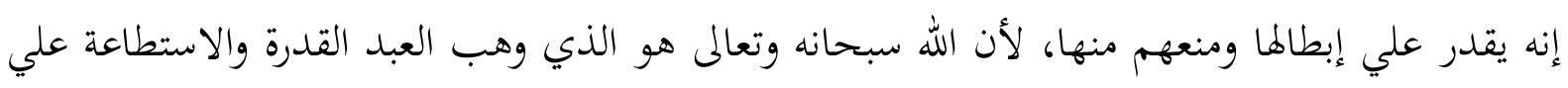

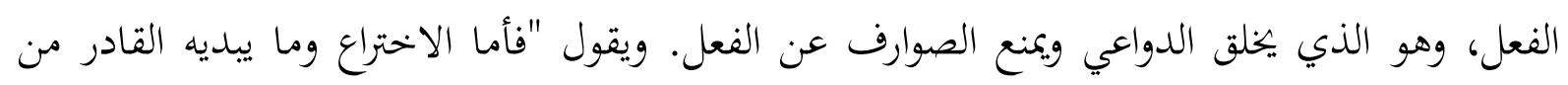

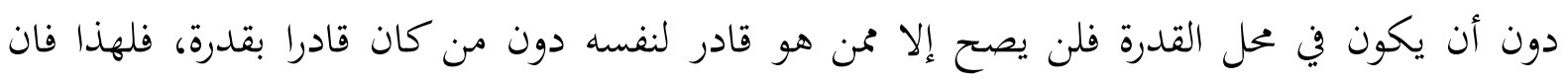

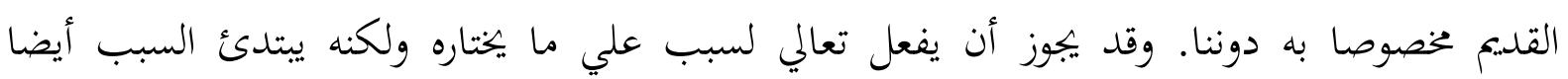

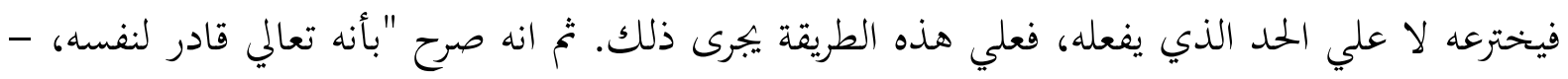

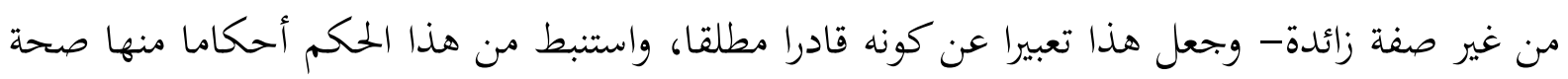

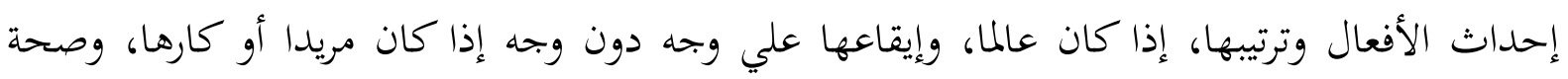

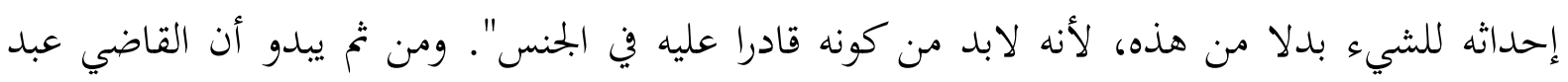

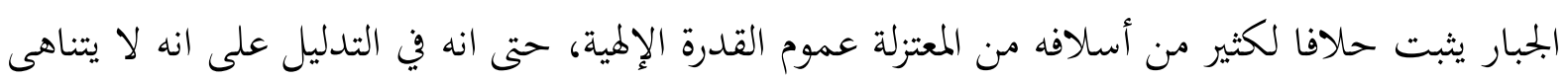

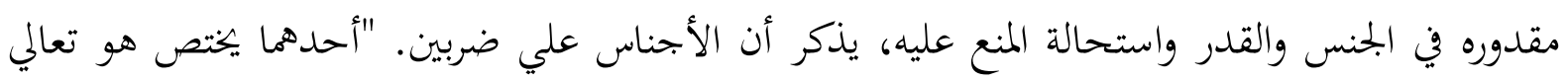

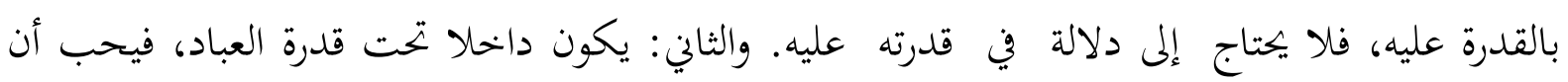

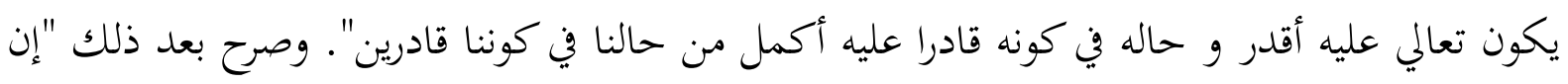

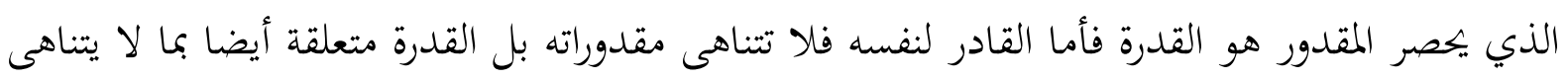


لتعلقها بما تتعلق به لذاتما" (al-Qadi `Abd al-Jabbar n.d.) وهو بذلك صرح بشمولية قدرة الله سبحانه وتعالى. وبناء على هذا فإننا نحتاج إلي النظر إلي حقيقة قول المعتزلة بإحداث الإنسان لفعله وخلقه، لأهم لم يحاولوا تضييق إطلاق القدرة أو الحد من عموم القدرة الإلهية، وأيضا فإهم وإن أجازوا إطلاق لفظ الخلق أو الاختراع على الله وعلى الإنسان فإهم يميزون بين معنى الخلق مضافا إلي الله وبينه مضافا إلي الإنسان، وهم يؤكدون في الوقت نفسه بأن اللفظ عند إطلاقه فإنه يتصرف بمعناه إلي الله تعالى الخالق وأن مقدورات العبد ليست إلا أعراضا فقط والتي هي الحركات والسكنات المتمثلة في أفعاله. بل إن القاضي عبد الجبار يرفض أن يكون إحداث الإنسان لفعله كالخلق الإلهي من عدم بالرغم مما تم عرضه من رأيه في معنى الخلق وتصريحه بأنه يجوز على الإنسان أن يفعل بتقدير سابق مثل فعل الإله، إلا أنه لا يصح أن يطلق عليه الخلق بالرغم من ذلك. حيث يقول: "أما الاختراع أو الخلق أو الإبداع فيتعذر منه (أي من العبد) لعلمنا أنه لا يقع على ما يدعوه الداعي إلي" وهذا النص يفيد نفى نسبة الخلق للإنسان. ثم يوضح في مكان آخر

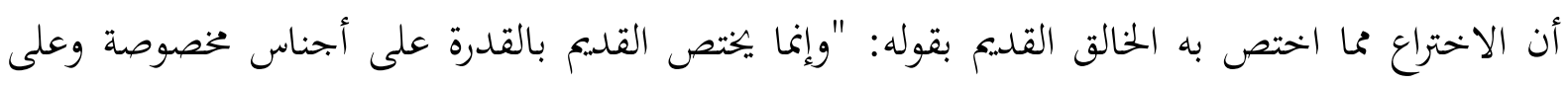
إحداث ما يقدر عليه على طريقة الاختراع لأمر يرجع إلي أنه قادر لنفسه" (al-Qadi `Abd al-Jabbar)

ويلاحظ قريب من هذا الرأي ما ذهب إليه الإمام يحي بن الحسين حيث قال: "إن الله خالق الأدوات وإيجاد الآلات في الأبدان وما يفرع منها فمن أفعال الإنسان" (al-Husayn n.d.) وهذا النص وان لم يخرج عن إثبات حرية الإنسان فانه يفيد أن الخلق الإلهي مخالف للخلق البشري. وبعد أن افرد القاضي لله سبحانه وتعالي بالخلق والاختراع بحده يفرق بين الحدوث والخلق حيث يصرح بأنه يمتنع عن تسميه الواحد منا بأنه خالق كما يمتنع حدوث الخلق علي الحقيقة منه بينما لا يمنع من تسمية الفاعل محدثا لفعله. ويبين أن علة إصراره الشديد علي القول بإحداث الفعل بالفاعل البشري هو نسبة الفعل وحدوثه حقيقة إلى العبد. حيث يقول: أما تسمية أفعالنا مخلوقة فغير جائزة علي الإطلاق. وقد منع السمع من إطلاق لفظ الخالق في العبد وان كانت اللغة لا تمنع تسمية بذلك، وليس يمنع أن يكون العبد محدثا ولا يسمى بهذا الاسم، إذ الممتنع أن يخرج عن حقيقة الفعلية والحدوث (al-Qadi `Abd al-Jabbar n.d.). وبذلك بحد أن القاضي بالرغم من انه يقول بحدوث الفاعلية البشرية وبالرغم من الآيات التي أوردها، فإننا بنحد محاولة لإثبات الحدوث لا تعنى إثباته الحنلق للإنسان لمنع الشرع له في ذلك. وذلك يشعر أن القاضي قد يقصد مفهوما آخر للإحداث البشرى للفعل غير ما قاله الآخرون من المعتزلة. وبتحليل 
معني الخلق الذي استخدمه المعتزلة في هذه القضية بحد انه وقع في معنيين مختلفتين: المعني الأول: الخلق يراد

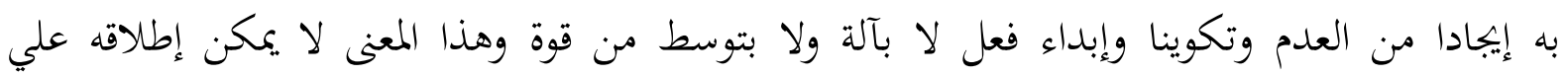

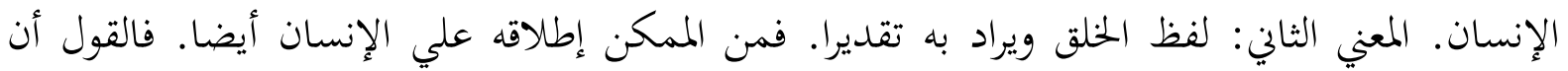

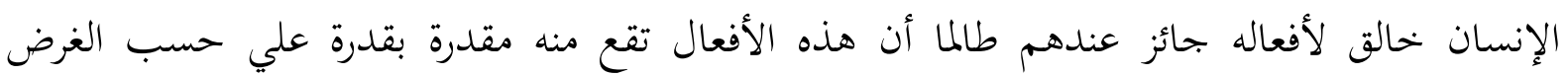
والداعي المطلوب. والقدرة أساس التقدير وهي ترتد إلى حال الإنسان (Dughaym 1992).

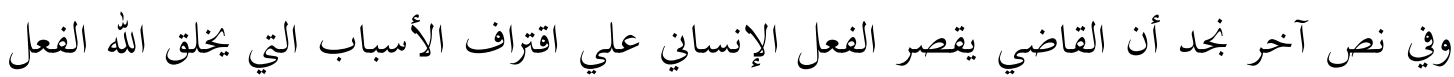

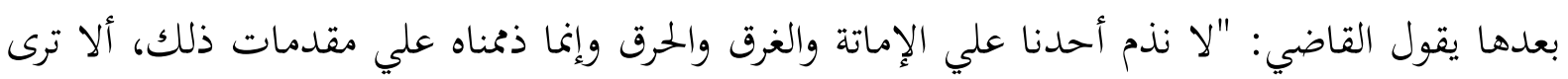

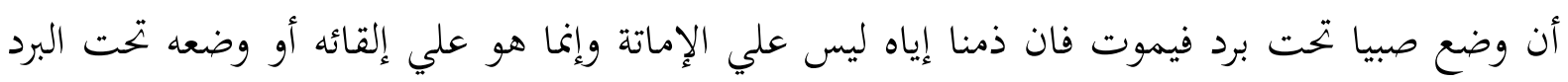

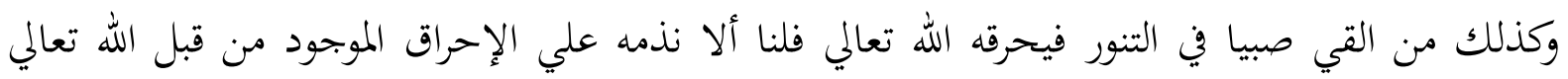

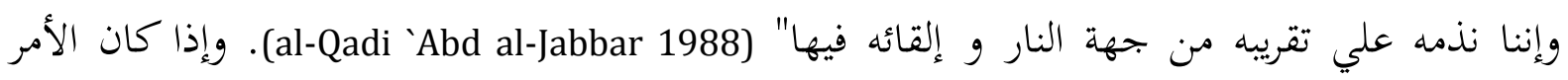

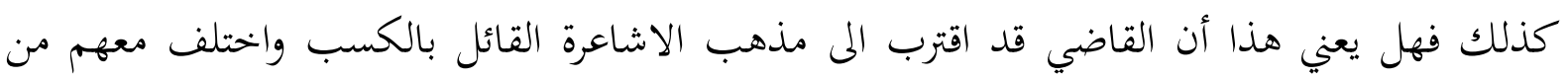

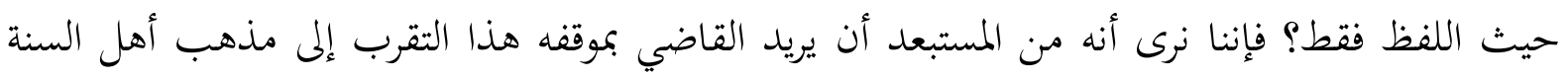

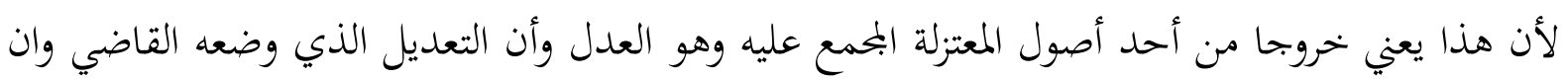

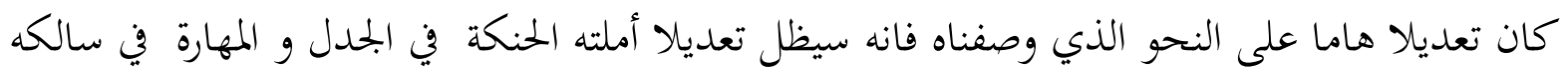

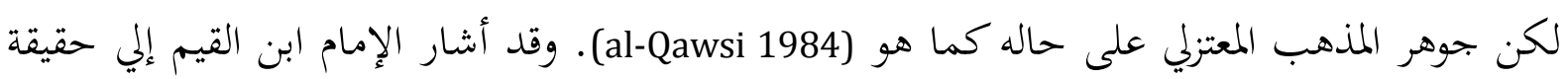

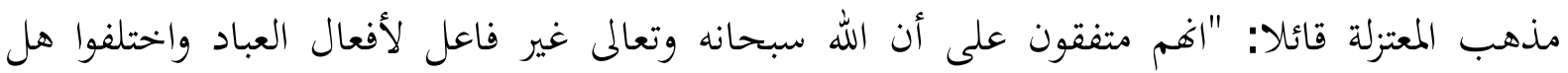

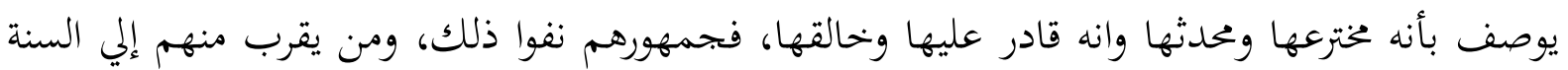

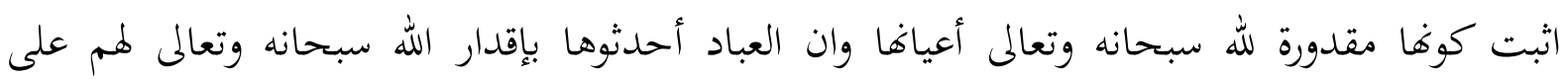
إحداثها" (Ibn al-Qayyim 1992) ثم يقول ابن القيم؛ وهؤلاء اقرب القدرية إلي السنة.

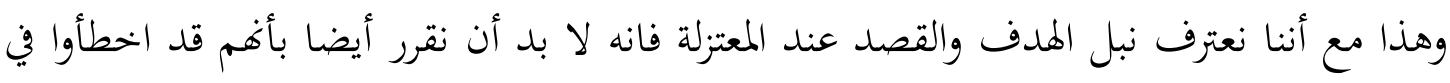

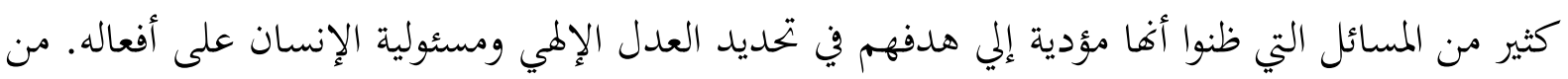

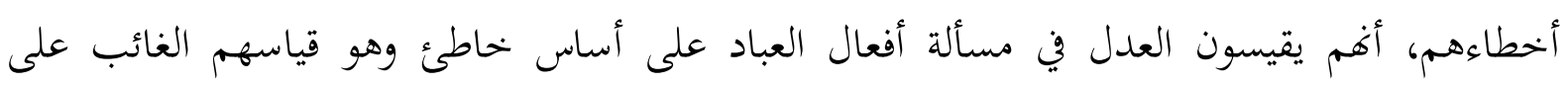

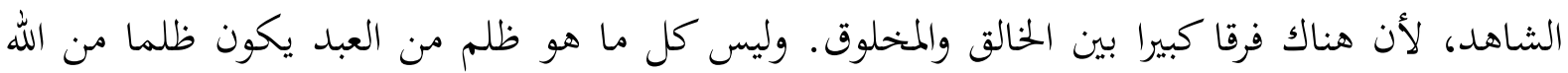

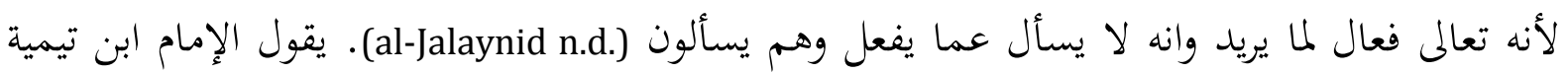

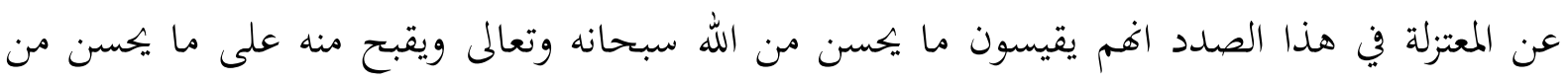


العبد ويقبح منه. فجعلوا يوجبون على الله سبحانه وتعالى ما يوجبونه على العبد، ويحرمون عليه ما يحرمونه

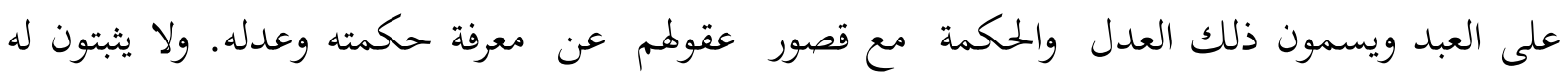

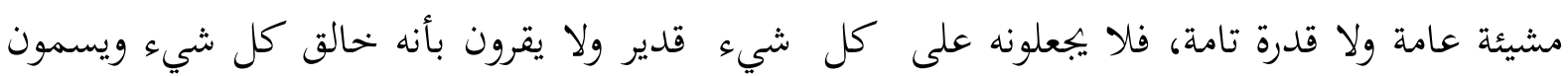

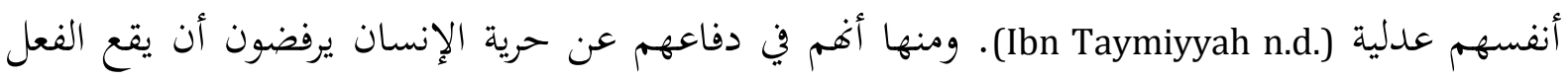

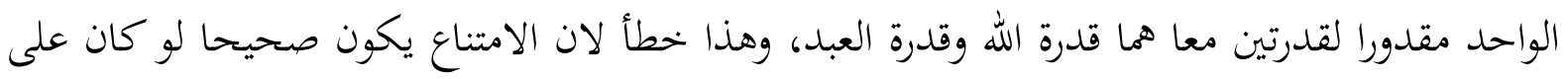
جهة واحدة ويكون التعلق بالفعل بينهما على طريق المزاحمة والممانعة، ولكن الحقيقة أن الفعل يتعلق بقدرة

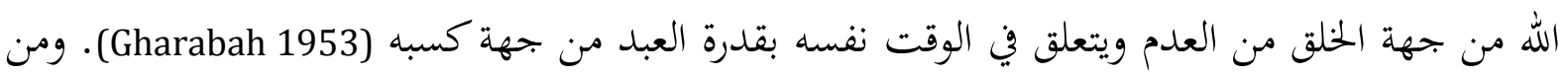

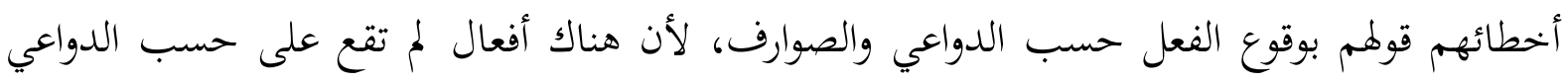

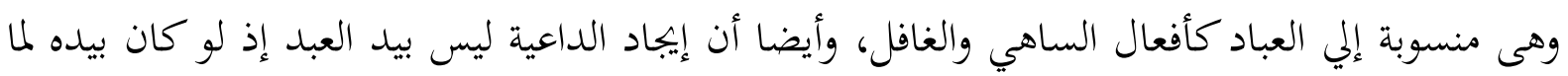
كانت الداعية داعية واكبر دليل على ذلك تردد العبد بين الدواعي وإنفساخ عزائمه بعد مستقرها وهما

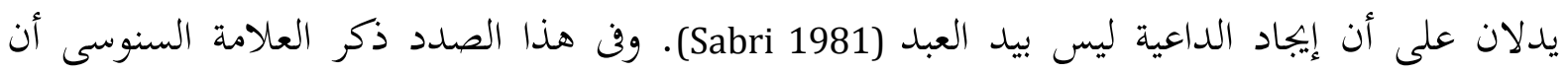

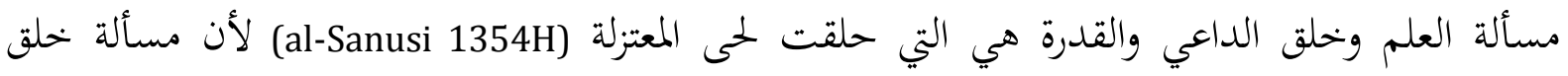

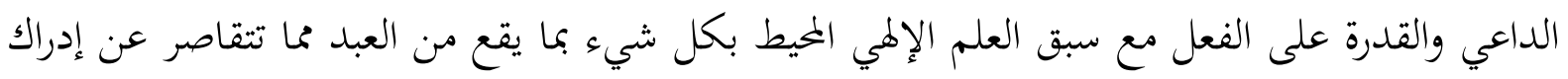
سره عقول البشر.

وقد ألزم الإمام الرازى على المعتزلة بأن قولهم بالداعية يؤدى إلى الجمبر من حيث لا يشعرون، قال:

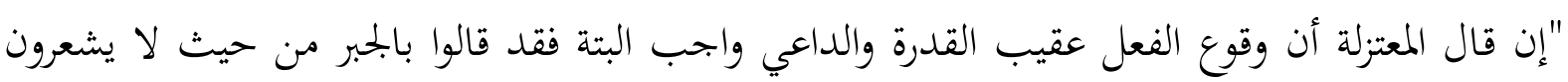

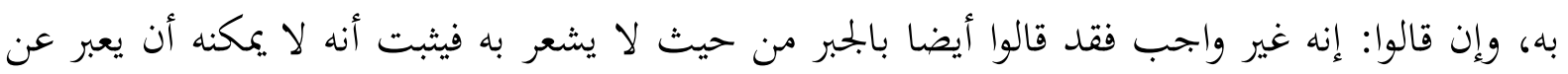

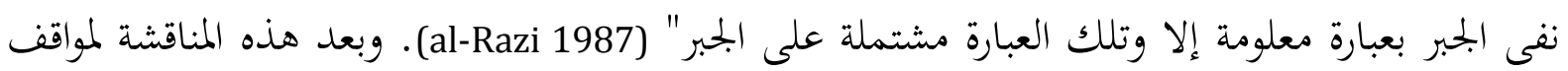

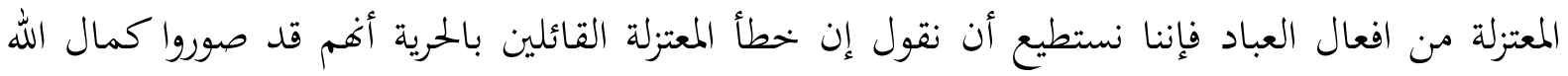
تعالى كما صورته لهم عقولهم فراحوا يدفعون عنه شوائب النقص ولا يريدون بذلك حدا لقدا لقدرة ولا جورا على ألوهية وإن ألزمهم خصومهم ذلك. وإن أساس المشكلة أن المعتزلة ينظرون إلي الأمر من ناحية تنزيه

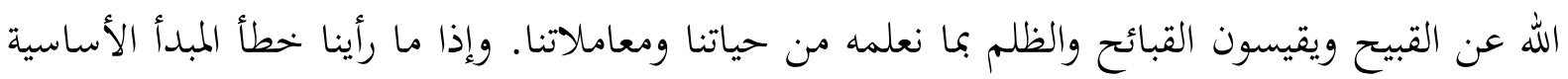

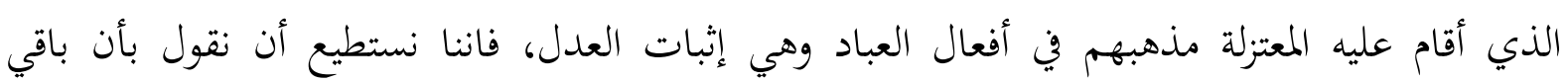

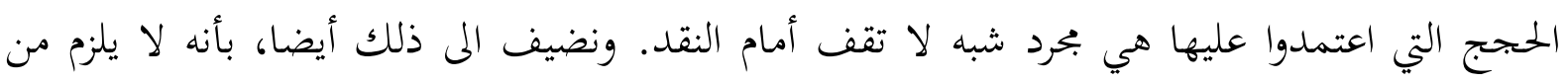

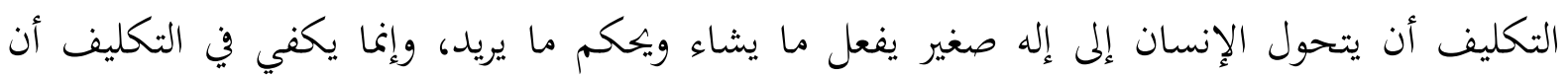

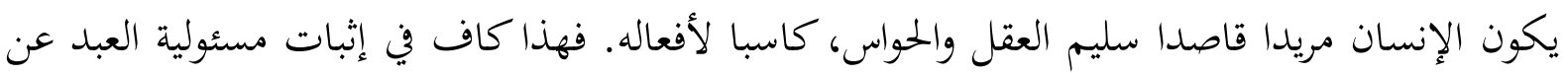




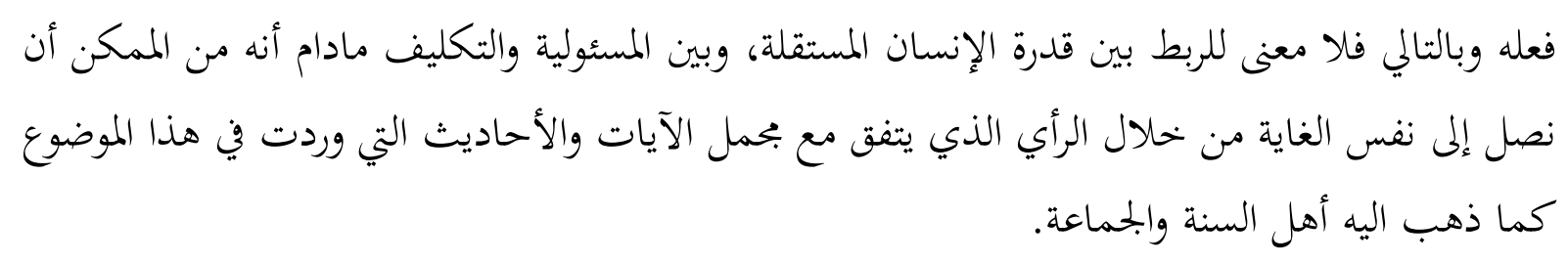

\section{References}

Al-Quran.

Ahmad Amin. 1994. Fajr al-Islam. Cairo: Maktabat al-Nahdah al-Misriyyah.

al-Baghdadi, Abu Mansur `Abd al-Qahir. 1988. Al-Farq bayn al-Firaq. Muhammad 'Uthman alKhashb (ed.). Cairo: Maktabah Ibn Sina.

Dughaym, Samih. 1992. Falsafat al-Qadr fi Fikr al-Mu 'tazilah. n.p.: Dar al-Fikr li al-Banani.

al-Dusuqi, Faruq. n.d. Al-Qada' wa al-Qadar fi al-Islam. Alexandria: Dar al-Da`wah.

Gharabah, Hamudah. 1953. Al-Imam Abu al-Hasan al-Ash `ari. Cairo. Matba`at al-Risalah.

al-Husayn, Yahya. n.d. Risalat al-'Adl wa al-Tawhid. n.p.: Dar al-Hilal.

al-Juwayni, Imam al-Haramayn. 1950. Al-Irshad ila Qawati` al-Adillah fi Usul al-Itiqad. Cairo: Maktabat al-Khanaji.

Ibn Qayyim. 1992. Shufa' al-'Alil. Beirut : Dar al-Kutub al-'Ilmiyyah.

Ibn Taymiyyah, Taqiyy al-Din Ahmad. n.d. Majmu' al-Fatawa. Cairo: Maktabah Dar Ihya' alKutub al-`Arabiyyah.

al-Jalaynid, Muhammad Sayyid. n.d. Madkhal li Dirasat al-Falsafat al-Islamiyyah. Cairo: Kuliyyat Dar al-'Ulum.

al-Jalaynid, Muhammad Sayyid. 1981. Qadiyyat al-Khayr wa al-Sharr fi al-Fikr al-Islami. n.p.: Matba`at al-Halabi.

al-Jurjani, Ali bin Muhammad. n.d. Sharh al-Mawaqif. Ahmad al-Mahdi (ed.). Cairo: Maktabat alAzhariyyah li al-Tiba`ah wa al-Nashr.

al-Qadi `Abd al-Jabbar, Ahmad. n.d. Al-Muhit bi al-Taklif. Cairo: Dar al-Misriyyah li al-Ta'lif wa alTurjumah.

al-Qadi `Abd al-Jabbar, Ahmad. n.d. a. Al-Mughni fi Abwab al-Tawhid wa al-`Adl. Cairo: Dar alMisriyyah li al-Ta'lif wa al-Turjumah.

al-Qadi `Abd al-Jabbar, Ahmad. 1988. Sharh Usul al-Khamsah. `Abd al-Karim 'Uthman (ed.). Cairo: Maktabah Wahbah.

al-Qawsi, Muhammad `Abd al-Fadil. 1984. Hawamish `ala al-`Aqidah al-Nizamiyyah. Cairo: Dar al-Tiba`ah al-Muhammadiyyah.

al-Razi, Fakhr al-Din. 1987. Al-Matalib al-'Aliyah min al-'Ilm al-Ilahi. Beirut : Dar al-Kutub alArabi.

Sabri, Mustafa. 1981. Mawqif al-'Aql wa al-'Ilm wa al-'Alim min Rabb al-'Alamin wa 'Ibadih alMursalin. Beirut : Dar Ihya' al-Turath al-'Arabi.

al-Sanusi, `Abd Allah Muhammad bin Yusuf. 1354H. Sharh al-'Aqidah al-Kubra. n.p.: Matba`ah Mustafa al-Babi al-Halabi.

al-Shahrastani, Abu al-Fath. 1990. Al-Milal wa al-Nihal. Beirut : Dar al-Kutub al-'Ilmiyyah.

al-Taftazani, Sa`d al-Din. 1987. Sharh al- 'Aqa'id al-Nasafiyyah. Ahmad Hijazi al-Saqa (ed.). Cairo: Maktabat al-Kuliyyat al-Azhariyyah.

al-Tayyib. 1348H. Al-Nashr al-Tayyib `ala Sharh al-Tayyib. Cairo: Dar al-Matba`ah al-Misriyyah bi al-Azhar.

al-Zawahiri, Muhammad al-Husayni. 1939. Al-Tahqiq al-Tam fi 'Ilm al-Kalam. Cairo: Maktabat alNahdah al-Misriyyah. 